Pteridines

Vol. 11, 2000, pp. $29-31$

\title{
The effect of tetrahydrobiopterin on the thermostability of human phenylalanine hydroxylase as studied by circular dichroism spectroscopy
}

\author{
Matthias Thórólfsson ${ }^{\mathrm{a}}$, Peter Fojan ${ }^{\mathrm{b}}$, Steffen B. Petersen ${ }^{\mathrm{b}}$ and Aurora Martínez ${ }^{\mathrm{a}}$ \\ ${ }^{a}$ Department of Biochemistry and Molecular Biology, University of Bergen, Årstadveien 19, N-5009 Bergen, \\ Norway, and 'Department of Life Sciences, University of Aalborg, Sohngaardsholmsvej 49, DK-9000 Aalborg, \\ Denmark
}

Presented at the $12^{\text {th }}$ International Conference on Pteridines and Related Biogenic Amines, St. Moritz, Switzerland, March $18^{\text {th }}-25^{\text {th }}, 2000$

\section{Introduction}

Mammalian phenylalanine hydroxylase (phenylalanine 4-monooxygenase, $\mathrm{PAH}$, EC 1.14.16.1) catalyzes the hydrox lation of L-phenylalanine (LPhe) to L-tyrosine (L-Tyr), the rate limiting step in the only catabolic pathway of phenylalanine. PAH is a non-heme iron-containing enzyme which depends on tetrahydrobiopterin $\left(\mathrm{BH}_{4}\right)$ to catalyze the incorporation of molecular oxygen into the ring of $\mathrm{L}$ Phe (1). A dysfunction of this enzyme caused by mutations in the PAH gene results in a serious disease in humans, phenylketonuria. It has been proposed that in vivo regulation of $\mathrm{PAH}$ is dependent primarily upon the actions of $\mathrm{L}$-Phe and $\mathrm{BH}_{4}(2,3)$. Thus, $\mathrm{L}-\mathrm{Phe}$ is considered to be an activator, while $\mathrm{BH}_{4}$ blocks this substrate activation by forming an inactive $\mathrm{BH}_{4}$ enzyme complex. This complex formation seems to control the metabolic availability of $\mathrm{BH}_{4}$ and is important in protecting the cofactor from degradation when L-Phe levels are low in the cell (2). Moreover, it has also been shown that $\mathrm{BH}_{4}$ protects rat $\mathrm{PAH}$ from proteolytic degradation of the $\mathrm{N}$-terminal region (4). In this work we have studied the stability changes induced on human PAH (hPAH) upon binding of $\mathrm{BH}_{4}$ and its oxidized analogue dihydrobiopterin $\left(\mathrm{BH}_{2}\right)$, using circular dichroism.

\section{Materials and Methods}

Purification of $h P A H$. Expression of recombinant wild-type hPAH in $E$. coli (TB1) as fusion protein with maltose-binding protein, purification of the fusion protein by affinity chromatography on amylose resin, cleavage by factor $\mathrm{Xa}$ and further purification of the tetrameric form by size exclusion chromatography was performed as described $(5,6)$. The concentration of purified hPAH was estimated by the absorbance at $280 \mathrm{~nm}$, using the absorption coefficient $A_{280}(1 \mathrm{mg}$ $\left.\mathrm{ml}^{-1} \mathrm{~cm}^{-1}\right)=1.0(5)$.

Circular dichroism (CD) detected thermal denaturation. $\mathrm{CD}$ temperature scan curves of $\mathrm{hPAH}$ were recorded on a Jasco J-715 spectropolarimeter (Jasco, Corp.) equipped with PTC-348WI Peltier element (Jasco, Corp.). Stock solutions (50 mM) of $\mathrm{BH}_{4}$ (Schircks Laboratories) were prepared in $10 \mathrm{mM}$ $\mathrm{HCl}$. Samples containing hPAH (15 $\mu \mathrm{M}$ subunit) in the absence and presence of either $0.5 \mathrm{mM} \mathrm{BH}_{4}$ or 0.5 $\mathrm{mM} \mathrm{BH}_{2}$ (Schircks Laboratories) were freshly prepared in $20 \mathrm{mM} \mathrm{Na}$-phosphate buffer, $0.2 \mathrm{M} \mathrm{NaCl}$, $\mathrm{pH} 7.0$, using quartz cuvettes with a path length of 1 $\mathrm{mm}$ for the measurments. The thermal denaturation of hPAH was monitored at $222 \mathrm{~nm}$ at a scan rate of 0.7 ${ }^{\circ} \mathrm{C} / \mathrm{min}$. Analysis of the data and the determination of the midpoint melting temperature $\left(T_{\mathrm{m}}\right)$ values were performed by noise reduction and differentiation of the scans using the Standard Analysis program provided with the $C D$ instrument.

\section{Results and discussion}

We have recently studied the thermostability of hPAH and the effects of truncations and L-Phe binding by infrared spectroscopy, differential scanning calorimetry and CD ( 7 and unpublished results). These studies show that the denaturation of the enzyme results in two unfolding transitions with $T_{\mathrm{m}}$-values at 45 and $54{ }^{\circ} \mathrm{C}$, corresponding to the $\mathrm{N}$ terminal regulatory and $\mathrm{C}$-terminal catalytic domains of hPAH, respectively (Fig. 1). Moreover, the addition of L-Phe stabilized both domains and increased domain-domain interactions (data not shown). We have now studied by $\mathrm{CD}$ the effects

Correspondence to: Dr. Matthías Thórólfsson, Deparment of Biochemistry and Molecular Biology, University of Bergen, Arstadveien 19, N-5009, Bergen, Norvay tel: 47-555864 48, fax: 47-55586400,e-mail: matthias.thorolfsson@pki.uib.no 

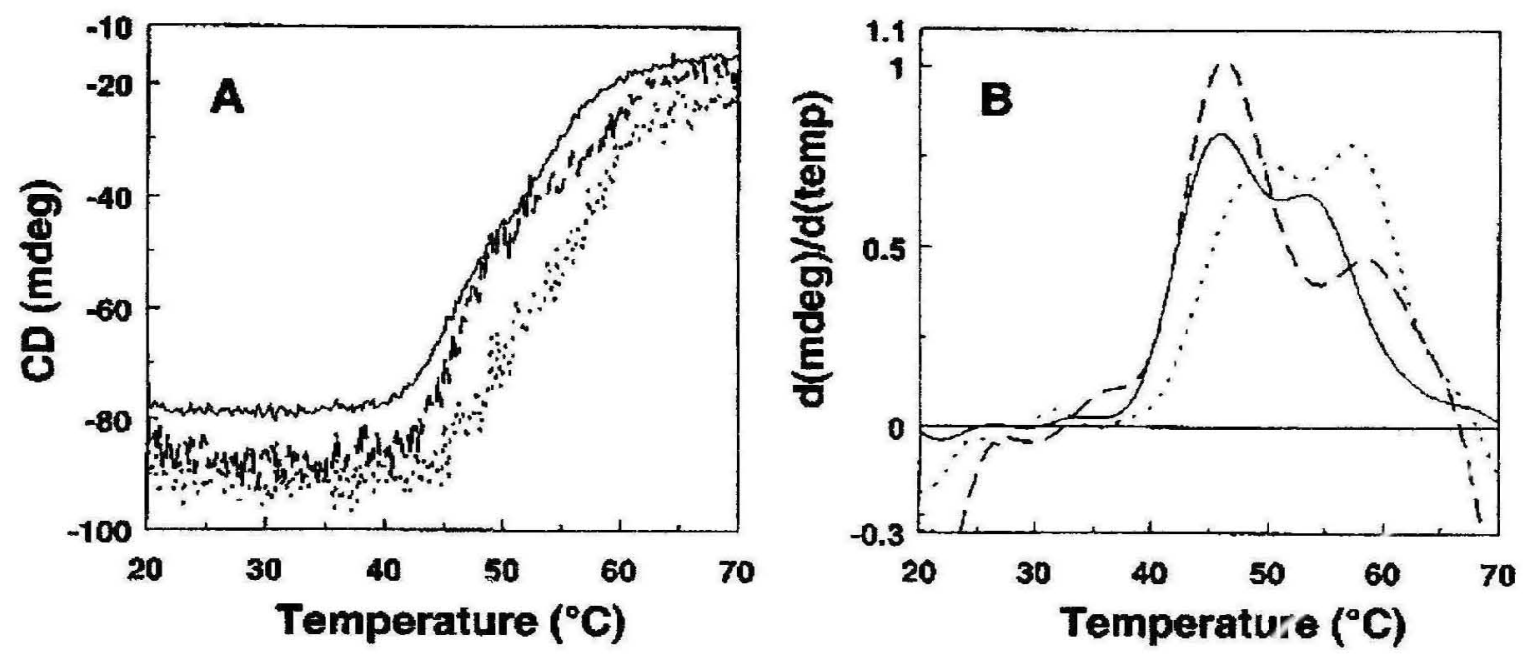

Figure 1. Heat induced unfolding of hPAH. (A) Change in the CD signal at $222 \mathrm{~nm}$ for hPAH, in the absence of ligand (--); in the presence of $0.5 \mathrm{mM} \mathrm{BH}_{4}(---)$; and in the presence of $0.5 \mathrm{mM}_{4} \mathrm{BH}_{2}(\cdots)$. (B) Differentiation of the data in A.

of $\mathrm{BH}_{4}$ and $\mathrm{BH}_{2}$ on the thermal induced denaturation of hPAH. Although none of these pterins induced significant changes in the CD spectrum (from 185 to $310 \mathrm{~nm}$ ) of hPAH at $25^{\circ} \mathrm{C}$ (data not shown) they seem to affect the stability and the domain interactions in the enzyme. Thus, in the presence of $\mathrm{BH}_{4}$ the $T_{\mathrm{m}}$ of the CD-detected thermal transition corresponding to the catalytic domain increased to $58{ }^{\circ} \mathrm{C}$ (Fig. 1 and Table 1). $\mathrm{BH}_{4}$ did not affect the $T_{\mathrm{m}}$ for the unfolding of the regulatory domain, although the transition becomes sharper and more separated from the second transition (Fig. 1). Although the subunit is more compact and stable in the presence of $\mathrm{BH}_{4}(4)$, the less concerted unfolding of the domains may indicate a weakening of the interactions between the regulatory and catalytic domains in $\mathrm{BH}_{4}$ complexed hPAH. Thus, the negative regulator $\mathrm{BH}_{4}$ has an opposite effect in the net interactions between the major domains than the activator L-Phe. In the presence of the cofactor analogue $\mathrm{BH}_{2}$ the overall thermostability of hPAH is increased (Fig. 1 and Table 1), which is a characteristic effect of the binding of a ligand to one of the domains of a protein with interacting domains.

Table 1. $T_{\mathrm{m}}$ values obtained for hPAH in the CD detected thermal denaturaration

\begin{tabular}{l|l|l} 
No ligand added & $0.5 \mathrm{mM} \mathrm{BH}_{4}$ & $0.5 \mathrm{mM} \mathrm{BH}_{2}$ \\
\hline 45 & 46 & 50 \\
54 & 58 & 58
\end{tabular}

The recent structural study on the conformation of $\mathrm{BH}_{2}$ bound at the active site of hPAH by NMR and docking (8) has shown that the dihydroxypropyl sidechain of $\mathrm{BH}_{2}$ interacts with Ser251 and Ala322 in the enzyme. These residues in turn have polar and non polar interactions with the inhibitory autoregulatory $\mathrm{N}$-terminal sequence (9). We have assumed that these interactions are the basis for the regulatory conformational changes induced by $\mathrm{BH}_{4}$ (8). However, our present results indicate the existence of subtle differences in the binding of the natural and the oxidized cofactor analogue and the conformational changes that they induce in hPAH. Moreover, the results obtained in this work with $\mathrm{hPAH}$ differ from those obtained with the homologous enzyme tyrosine hydroxylase, which, as seen by infrared-detected denaturation, seems to be significantly destabilized by the binding of both $\mathrm{BH}_{2}$ and $\mathrm{BH}_{4}(10)$. This different effect of the pterins could be related to the specific regulatory properties elicited by the natural cofactor on the two enzymes (1).

\section{References}

1. Kappock TJ. Caradonna JP Chem. Rev. 1996, 96: 2659-2756.

2. Xia T. Gray DW, Shiman R J. Biol. Chem. 1994, 269: $24657-65$.

3. Kaufman S Adv.Enzymol. Relat. Areas Mol. Biol. 1993. 67: 77-264

4. Iwaki M, Phillips RS, Kaufman S J. Biol. Chem. 1986, 261: 2051-6. 
5. Martínez A, Knappskog PM, Ólafsdóttir S, 8. Teigen K, Frøystein NA, Martínez A J. Mol. Biol. Døskeland AP, Eiken HG, Svebak RM, Bozzini M, 1999, 294: 807-23.

Apold J, Flatmark T Biochem. J. 1995, 306: 589-97. 6. Knappskog PM, Flatmark T, Aarden JM, Haavik J, Martínez A Eur. J. Biochem. 1996, 242: 813-21.

9. Kobe B, Jennings IG, House CM, Michell BJ, 7. Chehin R, Thórólfsson M, Knappskog PM, Goodwill KE, Santarsiero BD, Stevens RC, Cotton RG, Kemp BE Nat. Struct. Biol. 1999, 6: 442-8.

Martinez A, Flatmark T, Arrondo JL,Muga A FEBS 10. Flatmark T, Almås B, Knappskog PM, Berge SV, Lett. 1998, 422: 225-30. Svebak RM, Chehin R, Muga A, Martinez A Eur. J. Biochem. 1999, 262: 840-849. 